\title{
ÉTICA E ESTÉTICA NA FORMAÇÃO HUMANA
}

\author{
Amanda Pires Chaves68 \\ Pedro Laudinor Goergen69
}

\section{RESUMO}

Este artigo analisa a relação entre racionalidade, ética e estética na formação humana no contexto contemporâneo. Iniciando com o desenvolvimento da ciência e tecnologia e o debate sobre o processo de globalização, constata-se os limites e desafios do processo moderno de racionalização que se tornou o foco central e unilateral de todo o processo formativo. Na sequência, defende-se, com vistas a um conceito de formação integral do ser humano, a revalorização das dimensões ética e estética, na perspectiva mais ampla do cuidado de si. O objetivo é argumentar em defesa de um modelo de formação integral para as instituições educacionais em todos os níveis. Concluindo, argumenta em prol da formação de sujeitos críticos, corresponsáveis socialmente, capazes de agir como cidadãos na perspectiva do bem-estar social, em um cenário contemporâneo capitalista e globalizado, pleno de contradições, incertezas, desigualdades e injustiças sociais.

Palavras-chave: Racionalidade Moderna. Ética. Estética.

\section{ETHICS AND AESTHETICS IN HUMAN FORMATION}

\begin{abstract}
This article examines the relationship between rationality, ethics and aesthetics in human education in the contemporary context. Starting with the development of science and technology and the debate on the process of globalization, it is possible to notice the limits and challenges of the modern process of rationalization, which became the central and unilateral focus of the whole educational process. As a result, we put forth, with views to a concept of integral education of the human being, the revaluation of ethics and aesthetics, in the broader perspective of the care of themselves. The goal is to argue in defense of a model of integral education for educational institutions at all levels. In conclusion, it argues in favor of the education of critical subjects, socially co-responsible, able to act as citizens in terms of social welfare, in a contemporary capitalist and globalized scenario, full of contradictions, uncertainties, inequalities and social injustices.
\end{abstract}

Keywords: Modern Rationality. Ethics. Aesthetics.

68 Doutoranda em Educação pela Universidade de Sorocaba (UNISO). E-mail: amanda.pireschaves@gmail.com.

69 Professor da Universidade Estadual de Campinas (UNICAMP) e Universidade de Sorocaba (UNISO). E-mail: pedro.goergen@hotmail.com. 


\section{ÉTICA Y ESTÉTICA EN FORMACIÓN HUMANA}

\section{RESUMEN}

Este artículo analiza la relación entre racionalidad, ética y estética en formación humana en el contexto contemporáneo. A partir del desarrollo de la ciencia y tecnología y el debate sobre el proceso de globalización, los límites y desafíos del proceso moderno de racionalización que se convirtió en el foco central y unilateral de todo el proceso formativo. En la secuencia, se defiende, con vistas a un concepto de formación integral del ser humano, la revalorización de las dimensiones ética y estética, en una perspectiva más amplia del cuidado de sí. El objetivo es argumentar en defensa de un modelo de formación integral para las instituciones educativas en todos los niveles. Se concluye, argumentando a favor de la formación de sujetos críticos, corresponsables, capaces de actuar como ciudadanos en términos de bienestar social, en un escenario contemporâneo capitalista y globalizado, lleno de contradicciones, incertidumbres, desigualdades e injusticias sociales.

Palavras claves: Racionalidad Moderna. Ética. Estética.

\section{INTRODUÇÃO}

A história da humanidade é sem dúvida uma história de lutas e dificuldades, de avanços e retrocessos. Cada período histórico tende a se autoavaliar como mais difícil que os vividos anteriormente. Atualmente, também se fala e se escreve muito sobre o momento difícil que a humanidade está vivendo. Seria o momento presente mais difícil que os outros vividos no passado? Certamente, não é uma pergunta nada fácil de ser respondida, mas há um aspecto da contemporaneidade que parece profundamente novo e preocupante: pela primeira vez na história, a humanidade alcançou a capacidade e corre efetivo risco de autodestruição. Segundo muitos, para que isto ocorra basta seguir avançando pelos caminhos que estamos trilhando. As descobertas e avanços científico-tecnológicos, considerados o diploma de alforria do ser humano de sua submissão à teologia e à metafísica, se tornaram uma eminente ameaça à sobrevida da humanidade. Para evitar este desígnio autoimposto, é preciso uma radical autocrítica do ser humano, ou seja, uma reorientação de suas formas de pensar e de agir, hoje centradas nos 
interesses individuais e não coletivos. Isto, por sua vez, só parece possível mediante a reestruturação do processo formativo do ser humano. Um dos temas centrais deste processo de autoconscientização diz respeito à relação entre indivíduo e sociedade, entre a ação humana e o meio ambiente, entre interesses privados e coletivos, e aos desequilíbrios internos do ser humano entre seus interesses racionais, éticos e estéticos. As decisões sobre o processo formativo não se restringem, portanto, apenas a questões políticopedagógicas externas, mas à estruturação subjetiva do próprio ser humano.

$O$ presente ensaio tem por objetivo argumentar que 0 ideal de formação humana cidadã que busca a emancipação do homem como sujeito autônomo, crítico e corresponsável socialmente, deve ter como base e ponto de partida a harmonização subjetiva, racional, ética e estética do ser humano. Ponto de partida é o contexto social, político e econômico contraditório, fluido e incerto, exposto à permanente influência da evolução científico/tecnológica que, impregnado de racionalidade técnica, segmentação e dominação ideológica visa instrumentalizar o homem, impedindo a formação de cidadãos éticos e autônomos.

Neste contexto, justifica-se a realização de pesquisas sobre o tema do papel da ética e da estética no processo formativo das pessoas, visando à sua integralização como cidadãos dispostos a agir em prol da transformação social na perspectiva da construção de uma sociedade mais justa e democrática. Desse modo, argumenta-se neste ensaio a favor de uma urgente valorização das dimensões ética e estética como elementos essenciais ao projeto de formação integral do ser humano.

O artigo está estruturado da seguinte maneira: primeiramente, apresenta a discussão sobre o cenário contemporâneo, o processo de globalização e o avanço da ciência e tecnologia. Na sequência, estabelece a relação entre valores éticos e a construção da cidadania, mediada pela educação ético-moral. Finalmente, reflete sobre algumas questões da formação estética na contemporaneidade, na perspectiva do cuidado de si e do outro. 


\section{CENÁRIO CONTEMPORÂNEO: globalização, ciência e tecnologia}

O contexto contemporâneo se caracteriza por dois fenômenos de alto impacto na sociedade, intrinsecamente relacionados entre si: o avanço da ciência e tecnologia e a globalização. Ciência e tecnologia se apresentam como o caminho da salvação racional, neutra e definitiva, do ser humano e da humanidade. No entanto, na medida de sua evolução, sempre considerada garantia de um futuro melhor, ciência e tecnologia também deixam manifesto seu lado danoso, de risco e destruição. Exemplo clássico do problema da neutralidade da ciência e tecnologia é o espanto dos físicos quando se deram conta que sua genial descoberta da fissão nuclear resultou na construção da bomba atômica. Esta relação perigosa entre ciência e tecnologia não é um fato isolado uma vez que se tornou comum colocar a ciência a serviço de projetos econômicos e de poder que favorecem indivíduos ou grupos, em prejuízo dos interesses propriamente humanos. O problema, no entanto, não reside na ciência e tecnologia em si, mas no uso que se faz de suas conquistas. Esta apropriação é regida por interesses individuais, políticos, econômicos, de proveito, exploração e domínio.

Este cenário se torna ainda mais preocupante no contexto da globalização em que tudo se dissemina impactando rapidamente tanto as economias nacionais até as mais remotas regiões da terra, quanto as pessoas individualmente. Além da dimensão espacial, a globalização se torna cada vez mais célere pelos modernos sistemas eletrônicos de comunicação. O mundo se encontra conectado em densa e veloz rede de comunicação promovendo, por um lado, o desenvolvimento de forças produtivas e o acúmulo de riqueza e, de outro, a intensificação da pobreza e injustiça sociais. Assim, ciência e tecnologia se tornam a primeira e principal força produtiva e o principal meio ideológico de dominação do capitalismo. No entendimento de Dalbosco (2005, p. 164-165), 
isto significa dizer que técnica e ciência não só foram saberes aplicados ao desenvolvimento econômico da sociedade, sendo força propulsora da produção e acúmulo de riqueza da modernização social capitalista. Elas foram transformando-se progressivamente em fonte de dominação não só de natureza, mas também das pessoas, de suas instituições e das relações nelas estabelecidas.

Diante desse cenário de globalização e dominação, riqueza e pobreza, discrepâncias culturais, sociais e políticas, a questão da ética tem sido tema de grande relevância nas discussões acadêmicas. Antes do advento da modernidade e de suas principais estratégias - ciência e tecnologia -, "os conceitos de bem e mal eram definidos a partir de princípios metafísicos ou teológicos", [...], "foram sendo substituídos por útil e inútil, bem presos à serventia empírica" (GOERGEN, 1998, p. 58).

Relacionado aos conceitos de bem e mal, o agir ético seria agir segundo os princípios do bem, e o agir antiético seria agir segundo princípios do mal. Ao se substituir os conceitos de bem e mal, cultural e metafisicamente consolidados, pelos termos útil e inútil, orientados em circunstâncias empíricas, as ações humanas perdem sua conotação ética, passando a ser consideradas apenas em termos eficiência e utilidade, material e econômica. Assim sendo, bom passa a ser aquilo que é útil, produtivo, vantajoso; e mau aquilo que é inútil, improdutivo, sem proveito. Como se vê, ocorre um giro radical em termos de justificação ética do agir humano. Ao passo que o bem e o mal tinham como horizonte de julgamento a observação de valores de direito público e comum, útil e inútil são avaliados em termos de proveito privado, sem consideração dos prejuízos alheios.

Com o capitalismo e a prática incessante da busca de benefícios e vantagens particulares, atribui-se o qualificativo 'bom' a tudo o que auxilia no progresso e sucesso individual no mundo, principalmente, no plano econômico/utilitário como, por exemplo, o êxito na carreira, as amizades úteis, os objetos materiais de consumo e prazer, entre outros (VALLS, 2008). O indivíduo se antepõe à espécie, ao coletivo, numa espécie de suicídio 
coletivo com a realização da liberdade individual. Conceitos como 'cidadania' e 'autonomia' ficam contaminados pelo mal fatal do individualismo e do interesse privado.

Não se trata aqui de negar a importância do avanço da ciência e tecnologia, no mais responsáveis por grandes avanços na melhoria de vida, de conforto, de trabalho menos sofrido, maior longevidade, enfim, a solução ou alívio de muitos problemas diagnosticados no início da modernidade nos campos da saúde, da educação, da mobilidade, da produção de bens. Contudo, segundo Goergen (2015a, p. 310), é fato também "que a ciência pode representar uma ameaça à humanidade como um todo e, de outro, é extremamente difícil encontrar formas de mediação entre ciência e ética". Nesta perspectiva, na produção e no acúmulo de conhecimentos, predomina hoje a valorização do útil e do econômico, favorecendo as aspirações de poder, prazer, posse e satisfação pessoal.

Ao mesmo tempo em que a globalização e o avanço da ciência e tecnologia podem proporcionar resultados positivos à sociedade, também podem gerar riscos, como hoje se sabe, nos mais diferentes âmbitos, tanto para a natureza, relacionados à polvição e à destruição ambiental, quanto para o homem e a sociedade, com reflexos e desafios importantes na formação humana integral.

A história já nos ensinou, através de Auschwitz, das bombas
atômicas, das guerras convencionais ou eletrônicas e da destruição
do meio ambiente, que a razão celebrada como ciência e
tecnologia, é um instrumento tanto útil quanto perigoso (GOERGEN,
2005a, p. 69).

Na sequência, busca-se refletir sobre a importância dos valores éticomorais na construção da cidadania no contexto da sociedade contemporânea globalizada, capitalista, científica e tecnológica. 


\section{PRAGMATISMO ECONÔMICO E VALORES ÉTICOS: um desafio para a formação humana}

A história do homem na cultura ocidental está lastreada num processo de construção de modos e formas de vida expressos em conceitos, valores e costumes que se modificaram ao longo dos tempos e continuam sujeitos a permanentes processos de transformação histórica. Os diferentes fatores materiais, sociais, políticos e econômicos se encontram em permanente enredamento no ritmo do tempo, ora ao sabor de certa inércia histórica da conjugação de fatores, ora conduzida pela intervenção mais consciente do homem.

Na modernidade, pela via de uma inovadora racionalidade, acreditou-se na descoberta da chave do permanente progresso que garantiria uma nova era de luz em que o homem se livraria da ignorância e dos sofrimentos do passado. No entanto, como dizem Adorno e Horkheimer (1985, p. 38),

Na redução do pensamento a uma aparelhagem matemática está implícita a ratificação do mundo como sua própria medida. O que aparece como triunfo da racionalidade objetiva, a submissão de todo ente ao formalismo lógico, tem por preço a submissão obediente da razão ao imediatamente dado.

Apesar das consideráveis vantagens da ciência e tecnologia para a vida humana, são também enormes os riscos agregados ao domínio e uso da natureza. Tanto o crescimento do poder de intervenção e destruição, quanto o predomínio de uma cultura tecnicista e utilitarista trazem desafios difíceis de serem enfrentados. O aumento do poder de intervenção do homem, potencializado pela ciência e tecnologia, alcançaram tal autonomia que resultam em prejuízo do próprio ser humano e da sociedade. A filosofia do utilitarismo justifica não só o domínio, a exploração e a destruição da natureza, mas também a objetalização do próprio ser humano. Mais uma vez, Adorno e Horkheimer (1985, p. 41) vão ao ponto:

O processo técnico, no qual o sujeito se coisificou após sua eliminação da consciência, está livre da plurivocidade do 
pensamento mítico bem como de toda a significação em geral, porque a própria razão se tornou um adminículo da aparelhagem econômica que a tudo engloba.

Na medida em que os procedimentos matemáticos e científicos se tornaram a orientação autojustificada do humano, as consequências éticas são evidentes. Por isso, na contemporaneidade, o novo modelo de racionalidade, criado pela instituição da ciência e tecnologia, secundariza, quando não renega por completo, os valores éticos, morais na tomada de decisões, atribuindo primazia decisória à dimensão técnica e científica.

A dominação do homem se dá a partir do momento em que a racionalidade técnica não reconhece seus limites e "volta-se para o domínio e manipulação da própria vida, inclusive da vida humana" (GOERGEN, 2005b, p. 23). Portanto, torna-se urgente, no contexto contemporâneo, a busca pela emancipação e pela instauração de uma formação humana, visando não somente a dimensão racional, mas também a ética, voltada para o desenvolvimento do indivíduo e da sociedade.

O ideal de formação integral deve estar voltado para a cidadania, para a emancipação do homem e o adequado uso da razão, convertido na contemporaneidade, erroneamente, como o "ideal de homem submisso à ordem burguesa e aos seus interesses, disposto a aceitar as regras do mercado e a instrumentalização do ser humano a seu serviço" (GOERGEN, 2005b, p. 61), uma vez que os valores de cidadania foram desconstruídos por força do predomínio da razão instrumental.

Para Gruschka (2014, p.12) "a ética e a moral são grandezas de orientação inevitáveis para as mudanças sociais". Ainda que tratadas conjuntamente, moral e ética não são palavras sinônimas. Moral se refere a normas e valores que fundamentam ações de determinado grupo social, e ética diz respeito à elucidação dos fundamentos e justificativas dos valores no contexto das formas de convivência entre humanos. Segundo Severino (2005, p. 141-142), "a ética coloca-se numa perspectiva de universalidade, enquanto a moral fica sempre presa à particularidade dos grupos e mesmo 
dos indivíduos". Os valores morais são constituídos na existência humana e fazem parte da ética, uma vez que ela é "responsável por uma reflexão crítica sobre a moralidade, sobre o agir moral dos homens" (SEVERINO, 2005, p. 148).

A palavra ética vem do grego - Ethos, que significa costumes, tradições, valores, formas de convivência presentes na organização da vida humana. Em Homero, na llíada, foi encontrado pela primeira vez a grafia Ethos, com o significado de toca, caverna, "morada". Segundo Matos (2011, p. 116), anteriormente a atribuição do sentido ético, Ethos "é pertencimento numinoso a partir do qual construir e habitar são tarefas que participam do sagrado, da indivisão antiga entre os homens, a natureza e os deuses", ou seja, o modo de habitar é criação de valores.

Tal como aponta Severino (2005, p. 148), esta é uma investigação "inteiramente compromissada com as mediações históricas da existência humana, não tendo mais a ver apenas com ideais abstratos, mas também com referências econômicas, políticas, sociais, culturais". No contexto desta estreita relação entre a realidade e a postura ética se evidencia, segundo o mesmo autor, que

Nenhuma ação que provoque a degradação do homem em suas relações com a natureza, que reforce sua opressão pelas relações sociais, ou que consolide a alienação subjetiva pode ser considerada moralmente boa, válida e legítima (SEVERINO, 2005, p. 148).

Para que as ações dos indivíduos correspondam às expectativas sócioculturais, do ponto de vista ético-moral, é preciso que eles assumam uma formação humana ético-moral, orientada para a construção da cidadania. A formação do cidadão, por sua vez, implica autonomia, senso crítico e corresponsabilidade social. Isto se torna tanto mais relevante e urgente quanto mais forte for a percepção da sobrecarga de contradições que afligem a sociedade contemporânea. Uma das discrepâncias de maior destaque é a dissociação entre a formação profissional e formação cidadã. "O mundo econômico exige competência, competitividade, a busca de 
vantagens; a cidadania requer conhecimento e reconhecimento da diferença, solidariedade e busca do bem-estar social" (GOERGEN, 2005a, p. $65)$.

O desafio posto é formar cidadãos críticos, autônomos, responsáveis socialmente, capazes de reconhecer e respeitar as diferenças, bem como de agir ética e moralmente a favor do bem-estar da sociedade. Objetivo fácil de enunciar, mas difícil de realizar num cenário social globalizado, marcado por enormes decalagens sociais, de acúmulo de riqueza e intensificação da pobreza, de incertezas e constantes transformações estimuladas pela explosiva evolução da ciência e tecnologia, do ordenamento aparentemente incontornável do capitalismo produtivista e competitivo, das expectativas de enriquecimento e sucesso individual, num cenário de crescente desigualdade e injustiça social.

Se lançarmos um olhar sobre a história da modernidade, desde o ponto de vista da educação, nos deparamos com o debate muito diferenciado entre Rousseau e os enciclopedistas a respeito dos valores inerentes à ciência e tecnologia; encontramos também a dura polêmica entre Helvetius e Dideroł sobre educação; acompanhamos as polêmicas e elitistas ideias de Voltaire sobre a educação nacional; temos o discurso de Kant sobre a razão prática e a visão utilitarista de Bentham. Este cenário de múltiplas e diferenciadas vertentes nos transmite, não obstante, uma preocupação comum ou mesmo certa unanimidade a respeito do reconhecimento da necessidade da universalização dos ideais do esclarecimento mediante uma educação pública adequada. A despeito de todas as diferenças, a educação pública era considerada o eixo central do processo civilizatório. Disso se deduz que havia, também, uma preocupação importante e decisiva com a sociedade na perspectiva de sua eticidade.

Se, na sequência, nos voltamos para o presente, o quadro que se nos apresenta é bastante distinto do anterior. No cenário neoliberal contemporâneo, o que chama nossa atenção é a luta entre interesses privatistas pelo usufruto das conquistas da ciência e tecnologia. A promessa 
inicial da modernidade de escrever uma nova narrativa histórica mais favorável ao bem-estar da humanidade como um todo não se realizou. Ao contrário, as estatísticas a respeito da violência, das guerras, da fome, da miséria, da exclusão social são assustadoras.

O que mais preocupa neste cenário é que o papel do Estado como garantidor do bem comum, da justiça e do direito à educação, à saúde e segurança está sendo degradado e privatizado. Reduzimos a responsabilidade do Estado e entregamos o processo civilizatório, ou seja, os rumos do futuro da humanidade nas mãos dos interesses privados, econômico-privatistas, distantes de qualquer pudor ético. Um cenário, sem dúvida, sombrio e pouco animador. No entanto, se quisermos sobreviver enquanto humanidade, não nos resta alternativa, senão a de buscar novos caminhos para o futuro. Talvez a crise que vivemos, que não é apenas uma crise do capitalismo neoliberal, mas uma crise do modelo social como um todo, nos traga algum alento: o alento de termos que buscar novos consensos. Consensos em torno do que somos ou desejamos ser enquanto seres humanos, do que somos ou desejamos ser enquanto humanidade.

Neste sentido, ainda não conseguimos vislumbrar outra alternativa senão a de repensar a formação do ser humano, atualmente, exclusivamente concentrada na educação racional. Um olhar retrospectivo sobre a história moderna nos permite vislumbrar a importância, mas também os limites do racionalismo exacerbado e divisionista ao qual entregamos nossa sorte enquanto seres humanos. Precisamos recuperar a imagem e o sentido integral do ser humano que é racional, sim, mas ético e estético também. Já nos referimos, ainda que criticamente ao racional e falamos também da ética. A seguir, ainda que muito brevemente, vamos fazer referência à dimensão estética do humano. 


\section{ESTÉTICA, A DIMENSÃO ESQUECIDA DO HUMANO}

No centro do debate das questões éticas e morais se encontram, principalmente, temas relacionados aos aspectos e efeitos avassaladores da submissão do ser humano aos ditames do conhecimento científico e tecnológico, utilitário, materialista e pragmático. O grande desafio da educação é enfrentar o processo de dissolução da unidade original do ser humano em suas diferentes dimensões, em especial a racional, a ética e a estética. Esta segmentação tem como efeito a dissolução da integralidade do ser humano e, com isso, sua coerência identitária. Esta questão é da mais alta relevância uma vez que a mencionada dissolução do humano dificulta ou mesmo impede a sua emancipação.

O enfoque das discussões incide predominantemente sobre a crise da razão moderna produtivista e utilitarista, e a inseguridade da orientação moral. Apesar da relevância desse debate, inclusive para o futuro, não apenas dos indivíduos, mas da própria humanidade como um todo, ainda é tímida a preocupação com outra dimensão central do humano: a estética. Não se tem em conta que a constituição do ser humano está relacionada necessariamente à sensibilidade. Enquanto o racional se preocupa com a investigação do real e suas modificações e a ética busca ordenar as relações com o outro, a sensibilidade confere harmonia a todas as disposições, conferindo harmonia e integralidade ao humano. Segundo explica Goergen (2016, p.68)

É [...] tarefa da cultura [...], de um lado, o cultivo da faculdade sensível e, de outro, o cultivo da faculdade racional. 0 racional e o sensivel devem encontrar uma relação de reciprocidade na cultura; do contrário, teremos, necessariamente, um homem cindido. $\mathrm{Na}$ dialeticidade dessa relação, livre de monopolização unilateral, a pessoa se constitui harmônica e permanente na modificação. Do contrário, o homem perde o equilíbrio, como ocorre no transcurso da modernidade, num ritmo cada vez mais acelerado até chegar aos dias atuais em que a divisão e a segmentação se tornou, talvez, o desafio mais profundo e urgente. 
A estética é o terreno no qual os julgamentos racionais e éticos são suspensos, mas nem por isso a arte é um espaço neutro. A arte instiga o expectador a rever seus posicionamentos, a ter insights de natureza estética e não apenas epistêmica, a assumir novos posicionamentos ante os desafios que a vida coloca. Assim, diante de um conjunto de árvores, o sujeito racional tende a indagar sobre o sentido de elas ocuparem aquele espaço que poderia ser aproveitado para construir algum prédio, sobre a utilidade de sua madeira; o sujeito estético, ao contrário, aprecia e se sensibiliza ao ver as árvores, reconhecendo a importância de sua existência, tanto para a vida ambiental, quanto para a harmonia estética da natureza. A sensibilidade estética nos habilita a ter entendimentos e fazer juízos não marcados pelo utilitarismo; juízos esses tão ou mais importantes para o homem e para a humanidade quanto os juízes utilitaristas.

A palavra estética vem do grego aisthetiké, que significa o ato de admirar que envolve a sensibilidade do ser humano, sendo a estética um vetor de orientação para a razão e a ética. Segundo Angel Pino (2006, p.67), "orientar os sentidos para sentir bem [...] é procurar a forma de aperfeiçoar suas qualidades e atributos naturais para tirá-los do estado bruto", e, por conseguinte, "levá-los ao refinamento de um grau de sensibilidade às coisas que a cultura é capaz de dar", ou seja, fomentar nos indivíduos a conscientização do bem estar humano a partir da sensibilização do sentir-se bem, do viver bem, possibilita aos indivíduos uma passagem, do estado bruto (isento de sensibilidade), ao ser humano sensível, consciente e ético.

Caso este despertar da sensibilidade não seja realizado nos processos de formação humana, isto é, se não forem criadas condições favoráveis para uma progressiva educação estética, segundo Pino (2006, p. 67) "não é difícil prever as consequências negativas disso na vida das pessoas e na vida social". Neste sentido, desde sua origem, a estética se relaciona com as sensações causadas pelos acontecimentos do mundo na vida humana como um todo. 
Enquanto disciplina filosófica, a estética passou, inicialmente, por um período de contradições conceituais sobre "o que é arte, o que é gosto, o que é criação artística, o que é belo" (HERMANN, 2005, p. 25). Até o século XIX, a estética se vinculava à superficialidade, à devoção, à aparência, e era vista como oposta à ética. Somente a partir das teorias de Kant e Schiller, a estética passou a ser pensada como uma forma de sensibilidade para a vida moral.

No século XX, pela primeira vez, a indústria cultural (ADORNO, 1985), transforma a arte em produto comercial, destruindo, pela reprodutibilidade técnica, sua aura e seu poder de reflexão estética sobre a realidade. A influência do mercado teve como consequência o modelamento da cultura nas sociedades massificadas. A arte séria deve transcender a realidade e não se submeter a ela. Exatamente em sentido oposto ao da indústria cultural que trata a arte como produto subordinado ao sistema. "A arte leve acompanhou a arte autônoma como uma sombra. Ela é a má consciência social da arte séria". [...] "O que é novo", acrescentam os autores, "é que os elementos irreconciliáveis da cultura, da arte e da distração se reduzem mediante sua subordinação ao fim de uma única fórmula falsa: a totalidade da indústria cultural". (Adorno/Horkheimer, 1985, p. 127). Já em 1970, em Ästhetische Theorie (1970), Adorno destacava a dificuldade do indivíduo burguês de emitir um juízo de gosto; constata-se hoje a confirmação deste enunciado no contexto da barbarização, da globalização e do avanço da ciência e tecnologia. Esta barbarização carrega fortes traços de 'feiura' e desestetização do sujeito, da sociedade e do ambiente como um todo.

Para Hermann (2005), a estética, como sensibilidade desenvolvida, tem a capacidade de transformação; assim, a cultura estaria ligada ao sensivel, ao respeito às diferenças, a repressão às injustiças, a luta pelos marginalizados e oprimidos, contra todas as ações antiéticas. Para Goergen (2005a, p. 71) "antiético é tudo o que prejudica este sentido essencial de nossa vida de tornarmo-nos o que somos, isto é, seres humanos sociais". 
Para concluir, é oportuno retomar as dimensões da racionalidade e da ética tratados nos dois primeiros itens deste ensaio, referenciando-os à dimensão da estética. Um horizonte possível para alcançar tal objetivo parece ser projetar as três dimensões mencionadas no horizonte do conceito do 'cuidado de si' trabalhado por Foucault (2004) no seu livro A hermenêutica do sujeito. Partindo do pressuposto de que nem a racionalidade, nem a ética são capazes de, por si sós, salvarem o sujeito, Foucault desenvolve o conceito de cuidado de si como núcleo agregador do sujeito. O caminho está no conselho que Sócrates dá ao seu discípulo Alcibíades: "É preciso que reflitas um pouco sobre ti mesmo, que conheças a ti mesmo". Com isso, Sócrates deixa claro que "a necessidade do cuidado de si inscreve-se [...] não somente no interior do projeto político, como no interior do déficit pedagógico" (FOUCAULT 2004, p. 46 e 48). Para isto, é fundamental que Alcibíades saiba o que é este si mesmo, ou seja, o que é o sujeito, o que é o eu; portanto, precisa ampliar seu olhar para as dimensões do si mesmo para que, agregando-as no todo do sujeito, possa cuidar de si. O conhecimento racional lhe desvela que o cuidado de si "só pode formarse numa referência ao outro" [e] "deve estender-se a todos os indivíduos", vale dizer, incluindo a dimensão ética do eu. Com isso, o cuidado de si "torna-se coextensivo à vida" (Idem, p.106 e107).

Além dessa integralidade subjetiva, cabe ressaltar a dimensão social, ou seja, lembrar que a formação humana não acontece apenas individualmente; o outro tem um papel fundamental na constituição da identidade do eu. "Sem o outro não se constitui a identidade do eu, e sem essa identidade o eu não pode abrir-se para o outro" (GOERGEN, 2005a, p.71).

Na formulação de Foucault (2004, p.158)

O outro ou outrem é indispensável na prática de si a fim de que a forma que define esta prática atinja efetivamente seu objeto, isto é, o eu, e seja por ele efetivamente preenchida. Para que a prática de si alcance o eu, por ela visado, o outro é indispensável. 
Tendo como ponto de partida o Alcibíades de Platão, Foucault considera a constituição do eu a partir da temática do cuidado de si, com o significado de não se esquecer de si e ter o cuidado consigo mesmo, com sua vida orientada por regras próprias. Para Hermann (2005), retomando a moral grega, Foucault atribui ao cuidado de si como um modo de conduzir a vida, uma das bases da arte de viver, concebendo que esta relação do indivíduo com o seu eu, também é social, entre indivíduos.

Para Goergen (2005a, p. 71), "negar o outro ou destruí-lo é o mesmo que negar a si mesmo, enquanto ser humano". O homem caminha em direção ao outro a partir de si mesmo, mas a constituição da identidade do eu se dá a partir da inclusão do outro.

Volver o olhar para si implica, então, o olhar dos outros e o entorno sócio-histórico que, na verdade, é o elemento constitutivo do sujeito. Desviar os olhos dos outros e do mundo seria desviar o olhar de si próprio enquanto sujeito (GOERGEN, 2015b, p.8).

Com base nisso, Hermann (2005, p. 61-62) destaca que "a construção estetizada do sujeito ético não se dá através de regras morais categóricas, mas de acordo com a arte de viver que parte da escolha de práticas e fórmulas ideais", existentes na sociedade. Portanto, a ética depende das práticas humanas, centradas na escolha pessoal, com base na estética da existência, subjetiva e social. Esta, por sua vez, não se realiza apenas pela via racional como se imaginou desde o início da modernidade. A trajetória racionalista se olvidou, pelo menos em grande medida, da dimensão estética da sensibilidade humana baseada na experiência da harmonização e da proporcionalidade, condições necessárias para o equilíbrio social e subjetivo. A perspectiva estética é exterior às determinações racionalistas, estreitamente atreladas ao consumo e à utilidade. Livre do compromisso com a exatidão do discurso racional/científico, o olhar estético explora a sensibilidade para a beleza e a harmonia como condições do equilíbrio subjetivo e social. A ciência confia na capacidade racional do humano de encontrar respostas absolutas, 
seguras e verdadeiras, mas a crença na possibilidade de explorar os fatos por meio de uma teoria rigorosa e objetiva esbarrou nos seus limites de resolver os problemas e atender às aspirações genuinamente humanas. Percebendo que a ideia da verdade única não levaria à salvação da humanidade, Marx, Nietzsche, Freud e, mais recentemente Horkheimer e Adorno se encarregaram de formular as críticas ao encanto do sonho moderno.

A liberdade e independência artísticas, com sua própria legitimidade, livre dos compromissos com a utilidade, abre dimensões inusitadas que sugerem perguntas e dúvidas que abrem a perspectiva do equilíbrio, da harmonia e do respeito como inarredáveis dimensões do humano. Embora a obra de arte e a estética de modo geral não estejam isentas da absorção e integração pelo sistema, como bem mostram Adorno e Horkheimer (1985) no seu texto sobre a Indústria cultural, a transgressão estética não é inócua e estanque, mas se reinventa como baluarte de alternativa crítica ao sistema desumano e opressor.

Fecha-se, assim um círculo de relações entre racionalidade, ética e estética, configurando o ideal do sujeito integral, objetivo nuclear de um novo processo formativo que visa o homem integral que não se reduz aos estreitos limites da racionalidade técnico/científica muito mais preocupada com o sistema capitalista neoliberal do que com o bem-estar, a autonomia e a felicidade do ser humano. Os valores morais, éticos e estéticos devem estar presentes na constituição do eu, nas relações sociais, na formação humana de modo geral, em função do bem-estar da sociedade, da transformação da humanidade e da formação de cidadãos críticos e éticos em uma sociedade globalizada capitalista de contradições.

\section{CONSIDERAÇÕES FINAIS}

O fenômeno da globalização e o avanço da ciência e tecnologia, hoje marcados pelas diretrizes do capitalismo neoliberal, apesar de trazerem ganhos positivos para a sociedade, também têm acarretado problemas 
sociais e éticos na vida e formação humana. Por se tratar de um manejo dos avanços da ciência e tecnologia em favor de estratégias político/econômicas de domínio e instrumentalização do ser humano, tornase urgente uma reação que busque preservar a autonomia e dignidade do ser humano.

A visão pragmático/utilitarista, cada vez disseminada e proeminente na sociedade contemporânea, tende a subordinar os indivíduos e a sociedade como um todo aos seus interesses econômico/mercadológicos. O acúmulo de riqueza, por sua vez, produz desigualdades e degradação humana, gerando uma imagem injusta e dilacerada da sociedade. Embora não se possa atribuir esta situação a algum fator isolado, não há dúvida de que a ideologia pragmático/utilitarista constitui uma variável central para a configuração deste cenário, visto que o ser humano é objetalizado e posto a serviço do próprio sistema por ele construído ao longo da modernidade.

O utilitarismo tem suas raízes fincadas precisamente no chão do conceito de verdade e certeza, neutro e aético, da ciência e tecnologia. Por esta razão, o estímulo das posturas éticas e o fomento da sensibilidade estética, mediante o processo formativo integral do ser humano, pode representar uma reação humanizante frente a cenário desumanizante que marca o momento histórico em que vivemos. Em tempo: a valorização da ética e da estética na formação humana não representa oposição à cultura científico/tecnológica, como muitas vezes se pensa, mas são fundamentais e de caráter decisivo para o julgamento moral e a sensibilização estética. Sendo assim, torna-se imprescindível, no cenário contemporâneo capitalista globalizado, a discussão de temas, como os tratados neste artigo, da moral, da ética e da estética, como estratégia para despertar nos sujeitos posturas de vida favoráveis à transformação do sujeito, visando ao bem-estar social e uma humanidade melhor. 


\section{REFERÊNCIAS}

ADORNO, T. Ästhetische Theorie, Suhrkamp Verlag: Frankfurt a. M., 1970.

ADORNO, T.; HORKHEIMER, M. Dialética do esclarecimento, Rio de Janeiro: Jorge Zahar Editor, 1985.

DALBOSCO, C. A. Desafios ético-educacionais diante da crescente colonização do mundo da vida. In: LOMBARDI, José Claudinei; GOERGEN, P. (orgs.). Ética e educação: reflexões filosóficas e históricas. Campinas, SP: Autores Associados, 2005. p. 155-175.

FOUCAULT, M. A hermenêutica do sujeito. São Paulo: Martins Fontes, 2004.

GOERGEN, P. Ciência, sociedade e universidade. Educ. Soc., Campinas, v. 19, n. 63, p. 53-79, Ago. 1998.

GOERGEN, P. Ética e educação: o que pode a escola? In: LOMBARDI, José Claudinei; GOERGEN, P. (orgs.). Ética e educação: reflexões filosóficas e históricas. Campinas, SP: Autores Associados, 2005a. p. 59-95.

GOERGEN, P. Pós-modernidade, ética e educação. 2.ed. Campinas: Autores Associados, 2005b.

GOERGEN, P. A ética em pesquisa. Práxis Educativa, Ponta Grossa, v.10, n.2, p.301-315, jul/dez. 2015a.

GOERGEN, P. O cuidado de si como papel formativo da filosofia. 2015b. [não publicado].

GOERGEN, P. Formação humana hoje, In: RAJOBAC, R.; BOMBASSARO, L.C.; GOERGEN, P. Experiência formativa e reflexão, Caxias do SUl: EDUCS, 2016.

GRUSCHKA, A. Frieza burguesa: a frieza como mal-estar da cultura burguesa na educação. Campinas: Autores Associados, 2014.

HERMANN, N. Ética e estética: a relação quase esquecida. Porto Alegre: EDIPUCRS, 2005.

MATOS, O. Modernidade e Mídia: O crepúsculo da Ética. In: MIRANDA, Danilo Santos de. (org.). Ética e Cultura. São Paulo: Perspectiva. 2011. p. 115 - 127.

PINO, A. A produção imaginária e a formação do sentido estético. Reflexões úteis para uma educação humana. Pro-Posições, v. 17, n. 2, p.47-69, maio/ago. 2006.

SEVERINO, A. J. Educação e ética no processo de construção da cidadania. In: LOMBARDI, J. C.; GOERGEN, P. (orgs.). Ética e educação: reflexões filosóficas e históricas. Campinas, SP: Autores Associados, 2005. p. 137-153.

VALLS, Á. L. M. O que é ética? São Paulo: Brasiliense, 2008. 